\title{
The Role of Internet Pornography Use and Cyber Infidelity in the Associations between Personality, Attachment, and Couple and Sexual Satisfaction
}

\author{
Anik Ferron1, Yvan Lussier ${ }^{1 *}$, Stéphane Sabourin² ${ }^{2}$ Audrey Brassard ${ }^{3}$ \\ ${ }^{1}$ Université du Québec à Trois-Rivières, Québec, Canada \\ ${ }^{2}$ Université Laval, Québec, Canada \\ ${ }^{3}$ Université de Sherbrooke, Sherbrooke, Canada \\ Email: *yvan.lussier@uqtr.ca
}

How to cite this paper: Ferron, A., Lussier, Y., Sabourin, S. and Brassard, A. (2017) The Role of Internet Pornography Use and Cyber Infidelity in the Associations between Personality, Attachment, and Couple and Sexual Satisfaction. Social Networking, 6, 1-18.

http://dx.doi.org/10.4236/sn.2017.61001

Received: October 21, 2016

Accepted: November 16, 2016

Published: November 19, 2016

Copyright $\odot 2017$ by authors and Scientific Research Publishing Inc. This work is licensed under the Creative Commons Attribution International License (CC BY 4.0).

http://creativecommons.org/licenses/by/4.0/

\begin{abstract}
Although adults in romantic relationships currently show more openness to online sexual behaviors [1], these behaviors can nevertheless increase couple conflicts and instability [2]. In the current study, we assess the mediating role of Internet pornography use and cyber infidelity in the relationship between 1) personality and attachment, and 2) couple and sexual satisfaction. A total of 779 participants in couple relationships (average age $=29.9$ years) completed a series of online questionnaires. According to their responses, $65 \%$ of participants visited an adult site at least once during the six months preceding the study, while $16.3 \%$ did so multiple times per week. Path model results showed that Internet pornography use and cyber infidelity were sequential mediators between, on the one hand, personality and attachment, and on the other hand, couple and sexual satisfaction. The discussion highlights the importance of properly documenting the correlates of online sexual behavior to better understand new couple realities and dynamics.
\end{abstract}

\section{Keywords}

Internet, Pornography, Cyber Infidelity, Couple Satisfaction, Sexual Satisfaction, Personality, Attachment

\section{Introduction}

Accessible, anonymous, and affordable are terms that adequately describe the online pornography industry [3]. Although pornography is increasingly acceptable in Western cultures [4], its use can trivialize monogamy, lead to infidelity 
[1] [5], diminish sexual satisfaction, and even reduce sexual attraction to one's partner [6] [7] [8]. What's more, women's perception of their partner's pornography use is linked to couple dissatisfaction and sexual dissatisfaction [9]. However, sexual well-being can be enhanced when both partners use pornography [10]. Due to the sheer number of adult sites and their widespread appeal, researchers are increasingly interested in their role within couple dynamics [1] [2] [11] [12] [13].

The popularity of online pornography is an important factor in adult sexual dissatisfaction. Social surveys have shown that levels of sexual dissatisfaction can reach $60 \%$ [14]. The goal of the present study was to examine the role of Internet pornography ${ }^{1}$ use and cyber infidelity (sequential mediating variables) in the associations between 1) personality and attachment insecurities (exogenous variables), and 2) couple and sexual dissatisfaction (endogenous variables).

The definition of pornography varies for each culture and can differ depending on social context, personal beliefs, and individual experiences [15]. Sexual behaviors such as pornography use are constructed sexual scripts that have been learned through social interactions [16]. Traditional North American sexual scripts suggest that men have urgent sexual needs; their sexual behaviors are valued by society, whereas female sexuality is associated with emotion and commitment. In a North American context, a woman who is very sexually active has an inferior social status. These sexual scripts change depending on the nature of the interpersonal relationship. Modifying or maintaining sexual scripts is an active process involving significant human effort [17]. Today, breaking away from traditional sexual scripts can contribute to increased gender equity and offer more opportunities for sexual satisfaction [18].

Carroll et al. [4] define Internet pornography as online photos and/or videos presenting explicit nudity with the goal of enhancing sexual arousal. Internet pornography can also include erotic videos that focus less on genitalia and more on sensuality. Online sexual behaviors can include but are not limited to having an emotional component. These online activities can be performed alone (viewing pornography and masturbating) or in the presence of others via the Internet (webcam or live chat) [19]. If the individual is already involved in a romantic relationship, these behaviors can be considered acts of cyber infidelity.

\section{Prevalence and relational correlates of pornography use}

A recent study in the United States by Doran and Price [5] explored the pornography use of 20,000 men and women in romantic relationships. Their results showed that $17 \%$ of men and $3 \%$ of women had visited sexually explicit sites in the last 30 days. These results support similar findings by Carroll et al. [4], who found that, in a population of young adults, $27 \%$ of men-but only $2.2 \%$ of women-viewed pornography once or twice per week. Thus, men are more likely to consume pornography and do so for different reasons [20] [21] [22]. Women also reported less sexual arousal when viewing sexually explicit material

${ }^{1}$ For reasons of brevity, the term pornography will be used throughout the text when referring to explicitly sexual adult sites. 
[23]. Because men's pornography use is often problematic and compulsive, researchers have devoted less attention to women's patterns of use.

Some researchers have conceptualized pornography use as a modern form of sex addiction [24] [25]. However, few have attempted to demonstrate how the personality traits and attachment insecurities of individuals who use online pornography are related to cyber infidelity, couple satisfaction, and sexual satisfaction within adult romantic relationships.

Previous studies have shown that several personality traits (neuroticism, extroversion, openness to experience, agreeableness, and conscientiousness) are associated with couple dissatisfaction (see Malouff, Thorsteinsson, Schutte, Bhullar, \& Rooke, [26] for a review), and more rarely with sexual dissatisfaction [27]. Some of these traits might account for different online behaviors, such as pornography use and cyber infidelity. In turn, these behaviors might predict couple and sexual satisfaction. Until now, this model has not been the focus of empirical research.

In a study by Egan and Parmer [28], only neuroticism, agreeableness, and conscientiousness were related to men's pornography use. Heaven et al. [29] had similar results. These findings suggest that low altruism (agreeableness) and an active imagination (openness) are associated with pornography use. In the present study, we expect that these relationships will also reach significance. Emmers-Sommer, Hertlein, and Kennedy [30] showed that, regardless of gender, pornography use is related to openness and intentions of being unfaithful.

Very few studies have explored the relationship between personality and cyber infidelity, focusing primarily on in-person infidelity [31] [32]. Low levels of agreeableness and conscientiousness as well as extroversion are the principal characteristics associated with extra dyadic sexual involvement. The current study therefore aims to identify, in both women and men, if these different personality traits are associated with pornography use and cyber infidelity.

Studies have shown that the two key aspects of attachment-anxiety and avoidance insecurities - are related to couple dissatisfaction [33] and sexual dissatisfaction [34]. To our knowledge, the relationship between attachment, pornography use, and cyber infidelity is poorly documented [35]. People who score high on attachment-related anxiety and avoidance experience greater couple dissatisfaction [36] and sexual dissatisfaction, and pornography use is related to the quality of romantic relationships [35]. It seems relevant to consider the attachment insecurities of pornography users in order to better understand their interpersonal and sexual dynamics.

Attachment-related anxiety is characterized by a persistent fear of being unloved and rejected by one's partner. Anxiously attached individuals generally find sex reassuring and emotionally fulfilling [37] [38]. Attachment-related avoidance, on the other hand, is characterized by discomfort with intimacy and emotional dependence. Avoidantly attached individuals are more likely to satisfy their sexual desires without considering how this will affect their romantic partner [33]. In her review of the literature, Dewitte [39] recommended that researchers better document the mechanisms that connect anxiety and avoidance 
to sexual dissatisfaction.

In their study examining antecedents and consequences of men's pornography use, Szymanski and Stewart-Richardson [35] showed that gender role conflict in men is directly related to relationship and sexual satisfaction, but also indirectly related due to the sequential effects of attachment and pornography use. More specifically, indirect effects showed that gender role is linked positively to attachment-related anxiety and avoidance, which in turn is related to online pornography use. Only online pornography use was related to couple and sexual satisfaction. According to Szymanski and Stewart-Richardson, individuals with attachment-related anxiety are likely to use pornography because they feel vulnerable in their relationships. Individuals with attachment-related avoidance are less likely to be sexually intimate with a romantic partner, and pornography helps them satisfy their sexual needs. However, the abovementioned authors only studied men's attachment insecurities. In the present study, we explore these relationships both in men and women.

Regarding the relationship between attachment and cyber infidelity, research has primarily focused on in-person infidelity as opposed to online infidelity. Individuals with attachment insecurity are more inclined to seek out extradyadic sexual encounters [32] [40] [41] [42]. This is especially true for those with extreme attachment-related anxiety [43] [44] [45]. We suppose that both insecure dimensions of attachment are related to online infidelity.

\section{Pornography and infidelity}

Research has shown that visiting sexually explicit sites is associated with a greater likelihood of infidelity [1] [5], especially in men during their first years of marriage [5]. In a study by Stack, Wasserman, and Kern [46], adults who had used pornography more than three times in the last month were more likely to be unfaithful than adults who did not report extradyadic sexual behaviors. Wysocky and Childers [47] demonstrated that men were five times more likely to develop an online extramarital relationship if they had engaged in cybersex, while women were three times more likely. In sum, pornography use and cyber infidelity are important issues to consider when examining couple satisfaction and sexual satisfaction, and were therefore chosen as mediating variables in the present study. However, until now, no study has specified the direction of the relationship between pornography and cyber infidelity. Based on previous studies, we propose that pornography use is associated with online extra dyadic sexual behaviors.

\section{Pornography, couple satisfaction, and sexual satisfaction}

In general, pornography use is negatively associated with couple satisfaction [1] [2] [5] [8] [48] [49]. Willoughby et al. [12] have argued that the association between pornography use and couple dissatisfaction can be explained by men's aggressiveness, women's lower sex drives, and poor within-couple communication. Muusses et al. [48] have stated that men's pornography use is associated with low couple satisfaction and sexual satisfaction, which supports findings by Landripet and Štulhofer [50]. Women's use of pornography is linked to greater marital 
satisfaction [11] for both partners [2]. The combined results of these studies form the basis of the present model, which proposes that pornography use explains couple and sexual dissatisfaction through cyber infidelity. Based on previous studies, this relationship should differ depending on the participant's gender.

\section{Cyber infidelity, couple satisfaction, and sexual satisfaction}

In recent years, cyber infidelity has been increasingly studied [51] [52] [53]. The overall consensus is that cyber infidelity is potentially harmful to the couple [54] [55]. In some studies, the prevalence of cyber infidelity reached 63.6\% [47]. However, this statistic should be taken lightly as the participants were recruited via Ashley Madison, a social networking site for extramarital relationships. We propose that cyber infidelity is related to couple and sexual dissatisfaction. Because rates of infidelity among men are known to be higher than among women [56] [57] [58], gender should be addressed when looking at cyber infidelity.

\section{Objectives}

The current study proposes a cascade model where pornography use and cyber infidelity explain the associations between, on the one hand, personality and attachment, and on the other hand, couple and sexual satisfaction. We hypothesize that personality and attachment variables are related to pornography use, which in turn is associated with cyber infidelity. Finally, we propose that cyber infidelity is associated with couple and sexual satisfaction. Furthermore, because women and men show distinct patterns of pornography use (e.g., Hald \& Mulya [21]), we hypothesize that the model will differ according to gender.

\section{Methods}

\section{Participants}

The sample consisted of 779 French-Canadians (524 women and 255 men) living in Quebec who used a computer and were currently in a couple relationship. Since the study was conducted online and a number of participants dropped out midway, the number of participants changed from one questionnaire variable to the next. Among those who reported visiting adult sites during the past six months, 230 were men and 272 were women. Four inclusion criteria were applied: participants were in a couple relationship at the onset of the study, were between the ages of 18 and 65, had access to the Internet, and had completed the section of the online questionnaire about adult sites. Regarding the participants' education, $17.5 \%(n=102)$ had finished high school, 6\% $(n=35)$ had a diploma of vocational studies, $36.9 \%(n=215)$ had a college degree (in Quebec, College education generally spans 2 or 3 years after high school and precedes university undergraduate studies), $25.3 \%(n=147)$ had an undergraduate university degree, and $14.9 \%(n=87)$ had a graduate university degree. In total, 456 participants were employed at the time of the study (79.4\%). Participants were primarily heterosexual (91.4\%), while $3.1 \%$ were homosexual and $5.5 \%$ were bisexual. Regarding relationship status, $14.8 \%$ of the participants were in a couple relationship but were not cohabiting, $36.2 \%$ were married, $41.1 \%$ 
were common-law partners, and $7.9 \%$ were separated or divorced currently engaged in a couple relationship with a new partner. The average age of participants was 29.85 years $(S D=9.91)$ and the average length of their relationship was 6.36 years $(S D=6.57)$.

\section{Procedure}

Participants were recruited through local newspapers, Facebook, discussion forums, and emails sent out from March to September 2011. Participants had to visit the Survey Monkey website and complete an online questionnaire. The website's software ensures participants' confidentiality and follows strict ethical standards (including data encryption). Participants were informed of the study's objective: to examine the individual factors that motivate pornography use and assess their impact on the couple relationship. Participants were asked to complete a consent form. The study was approved by the Institutional Review Board. As compensation, five $\$ 100$ gift certificates were drawn at random and distributed to participants who had agreed to share their email address.

\section{Instruments}

Participants completed several questionnaires, including a demographic questionnaire. On average, participants completed the online questionnaires in 45 minutes.

Personality. Personality was assessed using 15 items [59] [60], which measured, on a five-point Likert scale, dimensions of the Five-Factor personality model [61]: neuroticism (low emotional stability, low adaptive capacity in response to stressors; $\alpha=0.79$ ), extroversion (highly involved in interpersonal relationships, confident; $\alpha=0.73$ ), openness to experience (curious about the world, interested in varied experiences; $\alpha=0.63$ ), agreeableness (friendly, empathetic, helpful; $\alpha=0.71$ ) and conscientiousness (highly controlling of emotions and impulses, organized, dependable; $\alpha=0.79$ ).

Attachment. The original questionnaire evaluating attachment in romantic relationships consisted of 36 items [62] [63] assessing two dimensions: anxiety and avoidance. Their internal consistency is high, varying between 0.84 and 0.86 . Lafontaine et al. [64] developed an abridged version of the attachment questionnaire. In the present study, ten items were retained. Cronbach's alpha coefficient values for the anxiety dimension $(\alpha=0.86)$ and the avoidance dimension ( $\alpha=0.85)$ were adequate.

Couple satisfaction. Couple satisfaction was assessed with a short four-item version of the Dyadic Adjustment Scale (DAS, Spanier [65]), developed by Sabourin, Valois, and Lussier [66]. Sabourin et al. [66] demonstrated that the abridged version is just as effective as the original 32-item version in distinguishing between distressed and happy couples. The abridged version had an adequate internal consistency ( $\alpha=0.84$ ) in the present sample.

Sexual satisfaction. Sexual satisfaction was assessed with five items (e.g., "Are you satisfied with the variety of sexual activities you engage in with your current partner?" "Are you satisfied with your sex life in general?") rated on a six-point Likert scale developed by Nowinsky and Lopiccolo [67]. Cronbach's alpha coefficient for the five items reached 0.93 . 
Adult sites. One item rated on a seven-point scale asked the respondents if they had visited an adult site (online explicit nude photographs-genitals, breasts, or buttocks-and/or XXX videos-sex, cunnilingus, fellatio, anal sex, etc.-of men and women over the age of 18$)$ in the past six months ( $1=$ no to $7=$ every day).

Cyber infidelity. Two items based on a dichotomous scale were developed to assess if emotional or sexual infidelity had occurred on the Internet: 1) "Have you ever been emotionally involved with someone other than your romantic partner on the Internet while you were in a stable couple relationship? (e.g., acted seductively, expressed or felt feelings of love, given compliments)" 2) "Have you ever had sexual exchanges with someone other than your romantic partner on the Internet while you were in a stable couple relationship? (e.g., watched someone sexually stimulate themselves)". The internal consistency coefficient was $\mathrm{KD}=0.56$.

One question was also developed to better understand how participants defined cyber infidelity. Six scenarios were presented and participants were asked to select those that described an act of infidelity: visiting adult sites, exchanging personal information via live chat, having sexual exchanges via webcam, having sexual exchanges without webcam, being a member of an adult site, and having cybersex via webcam.

\section{Results}

\section{Descriptive analyses}

Regarding the frequency of pornography use, results showed that $35.6 \%$ ( $n=$ $277)$ of participants had never visited an adult site, $15.8 \%(n=123)$ had only been once, $12.1 \%(n=94)$ went once a month, $6.8 \%(n=53)$ twice a month, $11.2 \%(n=87)$ once a week, and $16.3 \%(n=127)$ multiple times a week. Only $2.3 \%(n=18)$ visited adult sites every day. The $t$-test results $(t(777)=19.30, p<$ $0.001)$ indicated that men $(M=4.68, S D=1.7)$ visited adult sites more frequently than women $(M=2.18, S D=1.5)$. The effect size was 1.52 (Cohen's $d$ ), which is a strong effect. The percentage of participants who selected one or more of the six scenarios describing potentially unfaithful behaviors were: $12.1 \%(n=94)$ for visiting adult sites, $30.3 \%(n=236)$ for exchanging personal information via live chat, $82.9 \%(n=646)$ for having sexual exchanges via webcam, $76.9 \%(n=599)$ for having sexual exchanges without webcam, $27.3 \%(n=213)$ for being a member of an adult site, and $90.1 \%(n=702)$ for having cybersex via webcam.

\section{Preliminary analyses}

The bivariate correlations between personality traits, attachment, pornography use, cyber infidelity, couple satisfaction, and sexual satisfaction are presented in Table 1.

\section{Path model}

The path model was assessed using mediation analyses, based on procedures proposed by Preacher, Rucker, and Hayes [68]. The model confirmed the presence of sequential mediation effects, which implies that participants' pornography use and cyber infidelity are mediators of the relationship between 1) per- 
Table 1. Correlations among pornography use, personal, relational, and sexual variables $(n=779)$.

\begin{tabular}{|c|c|c|c|c|c|c|c|c|c|c|}
\hline Variable & 1 & 2 & 3 & 4 & 5 & 6 & 7 & 8 & 9 & 10 \\
\hline 1. Extroversion & - & & & & & & & & & \\
\hline 2. Agreeableness & $0.25^{\star *}$ & - & & & & & & & & \\
\hline 3. Conscientiousness & 0.00 & $0.17^{* *}$ & - & & & & & & & \\
\hline 4. Neuroticism & $-0.16^{\star *}$ & $-0.13^{* *}$ & -0.04 & - & & & & & & \\
\hline 5. Openness & $0.28^{\star *}$ & $0.28^{\star *}$ & 0.00 & $-0.20^{* *}$ & - & & & & & \\
\hline 6. Avoidance & $-0.16^{\star *}$ & $-0.19^{* *}$ & $-0.11^{* *}$ & $0.07^{\star}$ & $-0.12^{\star *}$ & - & & & & \\
\hline 7. Anxiety & $-0.23^{\star \star}$ & $-0.10^{* *}$ & $-0.10^{* *}$ & $0.38^{\star *}$ & $-0.16^{\star *}$ & $0.16^{\star \star}$ & - & & & \\
\hline 8. Pornography & 0.03 & $-0.08^{\star}$ & $-0.21^{\star *}$ & $-0.10^{* *}$ & $0.11^{\star *}$ & $0.17^{\star *}$ & 0.03 & - & & \\
\hline 9. Cyber infidelity & 0.05 & -0.00 & $-0.13^{* *}$ & -0.01 & 0.07 & $0.13^{* *}$ & $0.11^{* *}$ & $0.27^{* *}$ & - & \\
\hline 10. SS & $0.08^{*}$ & $0.09^{*}$ & 0.00 & $-0.09^{\star}$ & 0.05 & $-0.42^{\star *}$ & $-0.10^{\star *}$ & $-0.09^{*}$ & $-0.16^{\star *}$ & - \\
\hline 11. CS & $0.08^{*}$ & $0.14^{* *}$ & 0.00 & $-0.13^{* *}$ & 0.06 & $-0.57^{* *}$ & $-0.18^{\star *}$ & $-0.11^{\star *}$ & $-0.22^{\star *}$ & $0.67^{* *}$ \\
\hline
\end{tabular}

Note: $\mathrm{SS}=$ sexual satisfaction. $\mathrm{SC}=$ couple satisfaction. ${ }^{*} p<0.05 .{ }^{* *} p<0.01$.

sonality and attachment (exogenous variables), and 2) couple and sexual dissatisfaction (dependent or endogenous variables). The path model was estimated using Mplus [69]. The missing data was analyzed using the full information maximum likelihood estimation (FIML), which uses maximum likelihood to estimate the model's parameters using as much raw data as possible [70]. Three indices were used to verify the model's fit: the comparative fit index (CFI), the Tucker-Lewis index (TLI), and the root mean square error of approximation (RMSEA). Hoyle [71] has shown that a CFI and TLI above .90 and .95 indicate a satisfactory and excellent fit to the data, respectively, and RMSEA values equal or inferior to .08 are acceptable [72].

The proposed mediation model indices indicated that the theoretical model of the relationship between variables was a good fit to the data $\left(\chi^{2}(3)=1.547, p=\right.$ $0.67, \mathrm{CFI}=1.00, \mathrm{TLI}=1.02, \mathrm{RMSEA}=0.000[95 \% \mathrm{CI}=0.000,0.047])$. The Bootstrap method was used to test the significance of the indirect or mediating effects (using 5000 random samples, with replacement from the original sample) in order to construct bias-corrected confidence intervals. Analyses showed that all effects were significant at $p<0.05$.

Figure 1 shows that neuroticism, conscientiousness, attachment-related anxiety, and attachment-related avoidance were directly related to couple dissatisfaction. Avoidance also had a direct negative association with sexual satisfaction. Interestingly, avoidance explained couple and sexual satisfaction through pornography use followed by cyber infidelity, or simply through cyber infidelity (total direct and indirect effects).

As hypothesized, the analysis of indirect effects showed that pornography use did not directly explain couple or sexual satisfaction; rather, the relationship was mediated by cyber infidelity. Thus, low neuroticism, high openness, low conscientiousness, and high anxious or avoidant attachment explained pornography 


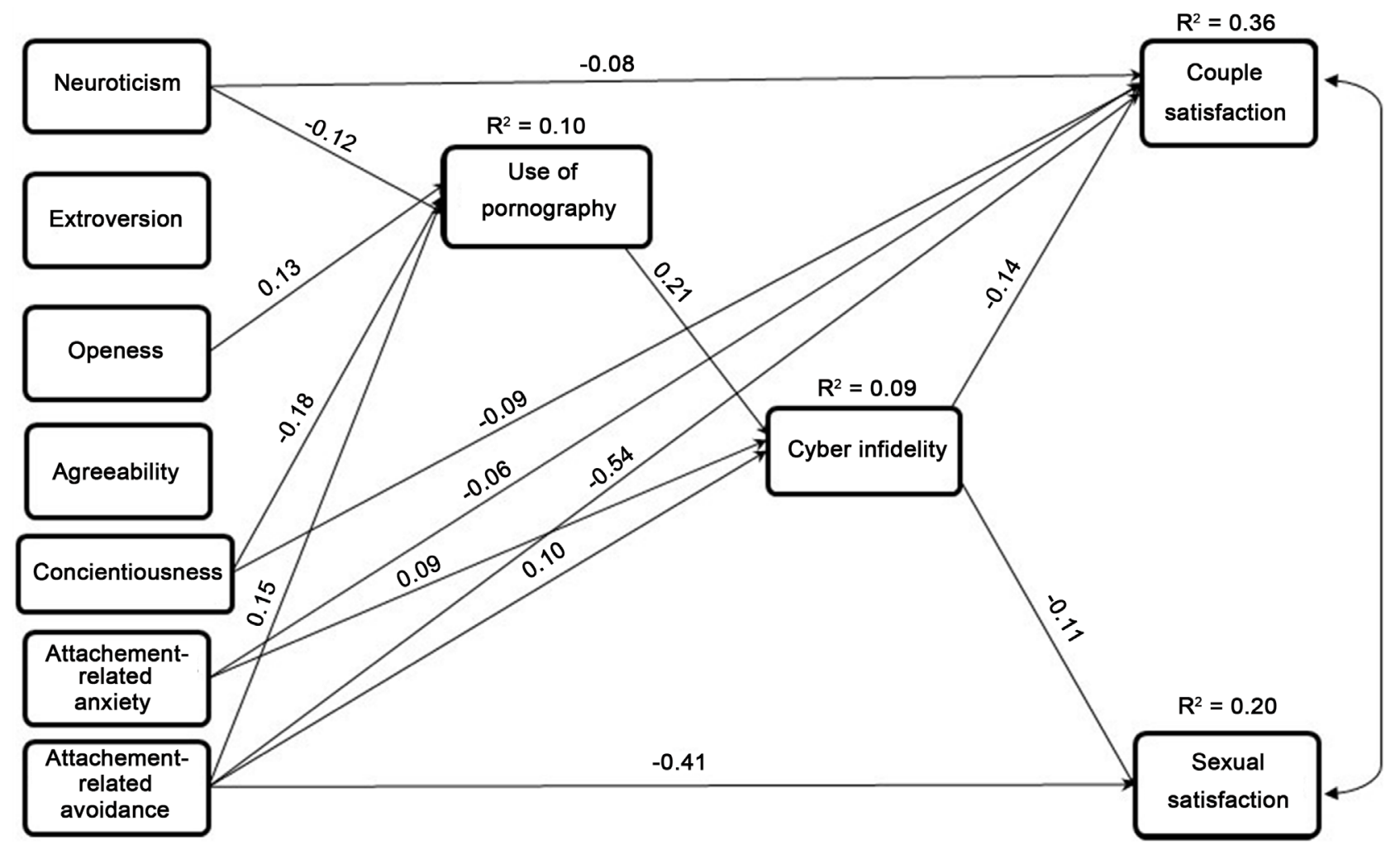

Figure 1. Model linking personality, attachment insecurities, pornography use, cyber infidelity, couple satisfaction, and sexual satisfaction. Only significant $(p<0.05)$ standardized regression coefficients $(\beta)$ are presented. The covariance between exogenous variables was estimated. The links between these variables are not presented to simplify the diagram.

use, which predicted cyber infidelity, which in turn predicted couple and sexual dissatisfaction. Regarding the second indirect relationship, attachment-related anxiety and avoidance were associated with cyber infidelity, which predicted couple and sexual dissatisfaction.

To test the second hypothesis, the model was estimated separately in men and women. Results showed a significant difference across genders $\left(\chi^{2}(6)=56.38, p=\right.$ 0.007). The model's mediation indices in men indicated that the theoretical model of the relationship between variables was a good fit to the data $\left(\chi^{2}(2)=\right.$ $0.64, p=0.73$, CFI $=1.00$, TLI $=1.11$, RMSEA $=0.000[95 \% \mathrm{CI}=0.000,0.088]$ ). Regarding personality traits, only low conscientiousness was related to pornography use. There was a direct relationship between low avoidance and couple satisfaction. Attachment-related anxiety and avoidance were also positively associated with cyber infidelity, but were not related to pornography use. Pornography use was positively correlated to cyber infidelity and negatively correlated to sexual satisfaction. Finally, cyber infidelity was only negatively related to couple satisfaction. There was no significant relationship between cyber infidelity and sexual satisfaction. Percentages of explained variance were small to moderate: viewing pornography $=5 \%$, cyber infidelity $=10 \%$, marital satisfaction $=$ $30 \%$, and sexual satisfaction $=16 \%$.

The model's mediation indices in women indicated that the theoretical model of the relationship between variables was a good fit to the data $\left(\chi^{2}(2)=4.91, p=\right.$ 
$0.09, \mathrm{CFI}=0.996, \mathrm{TLI}=0.931, \mathrm{RMSEA}=0.05[95 \% \mathrm{CI}=0.000,0.114])$. The significant relationships between the model's variables were similar to those in the model including all participants, except for six associations. Attachment-related anxiety was positively correlated to pornography use, while in the general model, it was positively correlated to cyber infidelity. Attachment-related avoidance was no longer significantly related to pornography use. Women's extroversion was negatively correlated to their couple satisfaction, while this relationship was not significant in the general model. Neuroticism was negatively correlated to sexual satisfaction, while in the model containing all participants, it was related to couple satisfaction. However, the relationship between women's neuroticism and their pornography use was not significant. Furthermore, women's pornography use was positively correlated to their sexual satisfaction. This positive association did not appear in the general model. Explained variance was small to moderate: viewing pornography $=12 \%$, cyber infidelity $=10 \%$, marital satisfaction $=39 \%$, and sexual satisfaction $=23 \%$.

\section{Discussion}

Many researchers and clinicians have attempted to identify variables related to couple and sexual satisfaction. Some have focused on personality [26] [27], others on attachment [33], sexuality [34], conflicts, violence, lack of commitment [73], and many other variables. New behaviors surrounding computer technologies, specifically pornography use and cyber infidelity, are social, cultural, and relational issues, and need to be included in new explanatory models. Our results indicated that pornography use is associated with couple and sexual difficulties through increased cyber infidelity. These original findings confirm the existence of "modern" forms of infidelity. While previous studies have suggested that these virtual relationships do not represent a "real" physical transgression of couple norms or a betrayal of one's partner [55], our empirical data is evidence to the contrary.

Cyber infidelity is a key link in the complex causal chain explaining variations in relationship quality. While many researchers have already shown that pornography use increases the probability of in-person extradyadic sex [5] [46] [47], cyber infidelity is another possible consequence. Future studies should explore the nature of the relationship between cyber infidelity and in-person infidelity. Online behaviors might vary in intensity along a continuum, from pornography use to live chat to emotional and sexual exchanges via webcam. To this end, future research should address overall Internet use (email, social networks, sexually explicit sites, etc.) to understand how various online situations can affect the development of cyber infidelity.

Path model results revealed several interesting relationships, particularly for neuroticism, intimacy avoidance, and sequential mediation. High neuroticism was directly related to low couple satisfaction. Furthermore, neuroticism was indirectly related to cyber infidelity through its negative relationship with pornography use. In turn, cyber infidelity was associated with couple and sexual satis- 
faction. These results confirm previous research findings showing that neuroticism is strongly related to couple dissatisfaction [26] [74] [75]. However, contrary to Egan and Parmer [28], our results indicate that low neuroticism is related to pornography use. In other words, our study suggests that calm and laid-back individuals tend to watch more pornography. Future studies should strive for a more complete assessment of neuroticism characteristics to better understand this counterintuitive result. Low conscientiousness was associated with pornography use, which also supports findings by Egan and Parmer. However, caution should be exercised when comparing results since the present study was not limited to individuals who were dependent on pornography. Only $2.3 \%$ of participants used pornography every day. A study by Widiger and Mullins-Sweatt [76] showed that low conscientiousness is often characterized by disorganization and carelessness, and very low levels of conscientiousness can be characterized by impulsiveness and negligence. Thus, an individual with low conscientiousness might exhibit deviant or compulsive online sexual behavior.

Finally, openness was positively related to pornography use. These results support findings by Emmers-Sommer et al. [30], who found that pornography users were less conservative when it came to sexual attitudes and behaviors, and Heaven et al. [29], who found that active imagination was associated with the desire to use pornography. Thus, pornography use seems to be explained by non-conventional traits, which reflect curiosity, imagination, and unrealistic expectations [76]. Surprisingly, extroversion was not a significant trait in the present model, even though previous studies have shown it to be a defining feature of individuals who use social networking sites [77] [78] [79], sexting behavior [80], engage in extramarital relationships, and use pornography [81]. Future studies should clarify these inconsistent results.

Cyber infidelity was also explained by attachment insecurity. Previous studies have established that attachment-related avoidance negatively predicts couple dissatisfaction and sexual satisfaction [33]. In the present study, our results suggested that both mediators-cyber infidelity and pornography use-can reflect a lack of commitment in the relationship, as well as a desire to seek out alternative relationships, both of which are common in avoidant individuals. Furthermore, if we assume that intimacy avoidant individuals are selfish when it comes to their sexual needs, as Mikulincer and Shaver [33] have suggested, it comes as no surprise that pornography use is part of their sexual repertoire [35]. In these situations, the Internet becomes a safe space, shielding avoidant individuals from all forms of commitment.

The direct relationship between attachment-related anxiety and couple satisfaction was not surprising, given the numerous studies on couple satisfaction and attachment insecurity [33]. Regarding the indirect relationship between anxiety and couple and sexual satisfaction via cyber infidelity, several studies focusing on in-person infidelity have already shown that these two variables are related [32] [40] [41] [42]. The results of the present study suggest that the activation of the attachment system is associated with a desire for virtual emotional 
and sexual experiences, which satisfy anxious individuals' need for love. These experiences in turn have negative repercussions on couple and sexual satisfaction. Through cyber infidelity, individuals seek out the reassurance that is lacking in their current relationship. Future research should examine if fulfilling their need for security through cyber infidelity emotionally satisfies anxious individuals.

Finally, the nature and strength of the relationships between personality, attachment, pornography use, cyber infidelity, and couple and sexual satisfaction varied between men and women. Depending on the gender, relationships involving personality or attachment would sometimes become less significant or disappear altogether. Similarly, depending on the gender, the trajectory of influence would sometimes pass through pornography use or skip this step entirely. In the latter case, cyber infidelity became the link between 1) attachment and personality, and 2) couple and sexual satisfaction. Pornography use was negatively related to sexual satisfaction for men, but positively for women. This difference must be emphasized. Other studies have also shown that women's use of pornography may be beneficial to their sexual satisfaction [1] [11]. These results suggest that women satisfy their sexual desires and fantasies through pornography. Emmers-Sommer et al. [30] have shown that pornography use in women lowers sexual inhibitions, enriches sexual activity, and increases couple closeness. In men, pornography use is associated with higher sexual desire, stimulation, and gratification. However, these effects may lead to decreased sexual desire towards their partner and decreased sexual satisfaction within the couple. These gender differences may reveal distinct patterns of motivation for pornography use: while men seek to increase their sexual arousal for masturbation, women seek to improve the quality of their sexual relationship with their partner [11]. A thorough examination of the motivations underlying pornography use in men and women is necessary to test this hypothesis.

\section{Limitations}

The present study has brought to light the potential role of different online behaviors, taking into account personal and relational variables. However, given the cross-sectional nature of the study, caution should be exercised when interpreting the results. Future studies might consider longitudinal designs using the actor-partner interdependence model (APIM; Kenny et al. [82]) to better understand what motivates both partners' pornography use. Concerning the causal direction among variables, future research should examine the contexts of pornography use and cyber infidelity, and clarify whether they constitute the cause or the consequence of couple and sexual dissatisfaction. Furthermore, our sample recruitment strategy might have limited the study. Other types of samples should be evaluated to generalize the models.

Another limitation was the conceptualization of pornography use and cyber infidelity variables. The definition of infidelity proved to be ambiguous. Some participants considered that pornography use was an act of infidelity, while oth- 
ers did not. Moreover, items presented low reliability. Future studies should better define emotional infidelity by including, for example, specific behavioral indicators (e.g., complimenting an individual with the goal of seducing them). Studies should also clarify the nature of the link between pornography use and cyber infidelity. Furthermore, a more exhaustive assessment of pornography users' personality traits [76] might have refined our results. For example, high neuroticism is characterized by fear, lack of confidence, and anxiety, while low neuroticism indicates obliviousness to danger and recklessness. These extremes can be harmful for Internet users. A thorough assessment of personality traits (e.g., sex addiction, immediate gratification of personal needs, compulsivity, high sexual needs, stress management) could lead to a better understanding of the motivations behind pornography use, regardless of individuals' frequency of use.

\section{Practical Implications}

As the pornography industry continues to grow, clinicians report that an increasing number of individuals are seeking out help to deal with sexual and relational difficulties associated with pornography use [5] [50] [83]. In addition, relationship issues associated with cyber infidelity seem to be on the rise [53]. Couples need to be able to define infidelity before they can establish clear rules about Internet use [49]. Therapists need to consider the importance of the Internet in romantic relationships, and should be aware of the possible behaviors that might predict infidelity, such as pornography use [84]. Online behaviors should be assessed on a continuum, ranging from simple online entertainment, to online dating, to cyber addiction [53]. An adequate assessment tool, such as the one developed by Rosenberg and Krauss [25], might help identify the various motivations behind individuals' pornography use (to learn different sexual positions, to decrease anxiety, to cope with sexual difficulties, to relieve boredom, to have fun, etc.). By gaining a fuller understanding of why individuals use Internet pornography, cyber infidelity might be better understood. Increased efforts should be made to develop appropriate treatments for cyber sexual behaviors and thus avoid couple dissatisfaction.

\section{References}

[1] Maddox, A.M., Rhoades, G.K. and Markman, H.J. (2011) Viewing Sexually-Explicit Materials Alone or Together: Associations with Relationship Quality. Archives of Sexual Behavior, 40, 441-448. https://doi.org/10.1007/s10508-009-9585-4

[2] Poulsen, F.O., Busby, D.M. and Galovan, A.M. (2013) Pornography Use: Who Uses It and How It Is Associated with Couple Outcomes. Journal of Sex Research, 50, 7283. https://doi.org/10.1080/00224499.2011.648027

[3] Cooper, A., Delmonico, D.L. and Burg, R. (2000) Cybersex Users, Abusers, and Compulsives: New Findings and Implications. Sexual Addiction and Compulsivity, 7, 5-29. https://doi.org/10.1080/10720160008400205

[4] Carroll, J.S., Padilla-Walker, L.M., Nelson, L.J., Olson, C.D., Barry, C.M. and Madsen, S.D. (2008) Generation XXX: Pornography Acceptance and Use among Emerging 
Adults. Journal of Adolescent Research, 23, 6-30. https://doi.org/10.1177/0743558407306348

[5] Doran, K. and Price, J. (2014) Pornography and Marriage. Journal of Family and Economic Issues, 35, 489-498. https://doi.org/10.1007/s10834-014-9391-6

[6] Albright, J.M. (2008) Sex in America Online: An Exploration of Sex, Marital Status, and Sexual Identity in Internet Seeking and Its Impacts. Journal of Sex Research, 45, 175-186. https://doi.org/10.1080/00224490801987481

[7] Drake, R.E. (1994) Potential Health Hazards of Pornography Consumption as Viewed by Psychiatric Nurses. Archives of Psychiatric Nursing, 8, 101-106. https://doi.org/10.1016/0883-9417(94)90040-X

[8] Manning, J. (2006) The Impact of Internet Pornography on Marriage and the Family: A Review of the Research. Sexual Addiction \& Compulsivity, 13, 131-165. https://doi.org/10.1080/10720160600870711

[9] Stewart, D.N. and Szymanski, D.M. (2012) Young Adult Women's Reports of Their Male Romantic Partner's Pornography Use as a Correlate of Their Self-Esteem, Relationship Quality, and Sexual Satisfaction. Sex Roles, 67, 257-271. https://doi.org/10.1007/s11199-012-0164-0

[10] Daneback, K., Traeen, B. and Mansson, S.A. (2009) Use of Pornography in a Random Sample of Norwegian Heterosexual Couples. Archives of Sexual Behaviors, 38, 746-753. https://doi.org/10.1007/s10508-008-9314-4

[11] Bridges, A.J. and Morokoff, P.J. (2011) Sexual Media Use and Relationship Satisfaction in Heterosexual Couples. Personal Relationships, 18, 562-585.

[12] Willoughby, B.J., Carroll, J.S., Busby, D.M. and Brown, C.C. (2015) Differences in Pornography Use among Couples: Associations with Satisfaction, Stability, and Relationship Processes. Archives of Sexual Behavior, 45, 145-158. https://doi.org/10.1007/s10508-015-0562-9

[13] Yucel, D. and Gassanov, M.A. (2010) Exploring Actor and Partner Correlates of Sexual Satisfaction among Married Couples. Social Science Research, 39, 725-738.

[14] Mulhall, J., King, R., Glina, S. and Hvidsten, K. (2008) Importance of and Satisfaction with Sex among Men and Women Worldwide: Results of the Global Better Sex Survey. The Journal of Sexual Medicine, 5, 788-795. https://doi.org/10.1111/j.1743-6109.2007.00765.x

[15] Ciclitira, K. (2002) Researching Pornography and Sexual Bodies. The Psychologist, 15, 191-194.

[16] Gagnon, J.H. (1999) Les usages explicites et implicites de la perspective des scripts dans les recherches sur la sexualité [Explicit and Implicit Use of Perspective Scripts in Research on Sexuality]. Actes de la recherche en sciences sociales, 128, 73-79. https://doi.org/10.3406/arss.1999.3515

[17] Laumann, E.O. and Gagnon, J.H. (1995) A Sociological Perspective on Sexual Action. In: Parker, R.G. and Gagnon, J.H., Eds., Conceiving Sexuality: Approaches to Sex Research in a Postmodern World, Routledge, New York, 183-214.

[18] Masters, N.T., Casey, E., Wells, E.A. and Morrison, D.M. (2013) Sexual Scripts among Young Heterosexually Active Men and Women: Continuity and Change. Journal of Sex Research, 50, 409-420. https://doi.org/10.1080/00224499.2012.661102

[19] Shaughnessy, K., Byers, S. and Thornton, S.J. (2011) What Is Cybersex? Heterosexual Students' Definitions. International Journal of Sexual Health, 23, 79-89.

[20] Hald, G.M. (2006) Gender Differences in Pornography Consumption among Young Heterosexual Danish Adults. Archives of Sexual Behavior, 35, 577-585.

https://doi.org/10.1007/s10508-006-9064-0 
[21] Hald, G.M. and Mulya, T.W. (2013) Pornography Consumption and Non-Marital Sexual Behaviour in a Sample of Young Indonesian University Students. Culture, Health \& Sexuality, 15, 981-996. https://doi.org/10.1080/13691058.2013.802013

[22] Morgan, E.M. (2011) Associations between Young Adults' Use of Sexually Explicit Materials and Their Sexual Preferences, Behaviors, and Satisfaction. Journal of Sex Research, 48, 520-530. https://doi.org/10.1080/00224499.2010.543960

[23] Goodson, P., McCormick, D. and Evans, A. (2000) Sex on the Internet: College Students' Emotional Arousal When Viewing Sexually Explicit Materials On-Line. Journal of Sex Education and Therapy, 4, 252-260.

[24] Grubbs, J.B., Volk, F., Exline, J.J. and Pargament, K.I. (2015) Internet Pornography Use: Perceived Addiction, Psychological Distress, and the Validation of a Brief Measure. Journal of Sex \& Marital Therapy, 41, 83-106. https://doi.org/10.1080/0092623X.2013.842192

[25] Rosenberg, H. and Kraus, S. (2014) The Relationship of "Passionate Attachment" for Pornography with Sexual Compulsivity, Frequency of Use, and Craving for Pornography. Addictive Behaviors, 39, 1012-1017. https://doi.org/10.1016/j.addbeh.2014.02.010

[26] Malouff, J.M., Thorsteinsson, E.B., Schutte, N.S., Bhullar, N. and Rooke, S.E. (2010) The Five-Factor Model of Personality and Relationship Satisfaction of Intimate Partners: A Meta-Analysis. Journal of Research in Personality, 44, 124-127. https://doi.org/10.1016/j.jrp.2009.09.004

[27] Fisher, T.D. and McNulty, J.K. (2008) Neuroticism and Marital Satisfaction: The Mediating Role Played by the Sexual Relationship. Journal of Family Psychology, 22, 112-122. https://doi.org/10.1037/0893-3200.22.1.112

[28] Egan, V. and Parmar, R. (2013) Dirty Habits? Online Pornography Use, Personality, Obsessionality, and Compulsivity. Journal of Sex \& Marital Therapy, 39, 394-409. https://doi.org/10.1080/0092623X.2012.710182

[29] Heaven, P.L., Crocker, D., Edwards, B., Preston, N., Ward, R. and Woodbridge, N. (2003) Personality and Sex. Personality and Individual Differences, 35, 411-419. https://doi.org/10.1016/S0191-8869(02)00203-9

[30] Emmers-Sommer, T., Hertlein, K. and Kennedy, A. (2013) Pornography Use and Attitudes: An Examination of Relational and Sexual Openness Variables between and within Gender. Marriage \& Family Review, 49, 349-365. https://doi.org/10.1080/01494929.2012.762449

[31] Shackelford, T.K., Besser, A. and Goetz, A.T. (2008) Personality, Martial Satisfaction, and Probability of Marital Infidelity. Individual Differences Research, 6, 13-25.

[32] Weiser, D.A. and Weigel, D.J. (2015) Investigating Experiences of the Infidelity Partner: Who Is the "Other Man/Woman"? Personality and Individual Differences, 85, 176-181. https://doi.org/10.1016/j.paid.2015.05.014

[33] Mikulincer, M. and Shaver, P.R. (2010) Attachment in Adulthood: Structure, Dynamics, and Change. Guilford Press, New York.

[34] Brassard, A., Péloquin, K., Dupuy, E., Wright, J. and Shaver, P.R. (2012) Romantic Attachment Insecurity Predicts Sexual Dissatisfaction in Couples Seeking Marital Therapy. Journal of Sex \& Marital Therapy, 38, 245-262. https://doi.org/10.1080/0092623X.2011.606881

[35] Szymanski, D.M. and Stewart-Richardson, D.N. (2014) Psychological, Relational, and Sexual Correlates of Pornography Use on Young Adult Heterosexual Men in Romantic Relationships. The Journal of Men's Studies, 22, 64-82. https://doi.org/10.3149/jms.2201.64

[36] Mikulincer, M., Florian, V., Cowan, P.A. and Cowan, C.P. (2002) Attachment Secu- 
rity in Couple Relationships: A Systemic Model and Its Implications for Family Dynamics. Family Process, 41, 405-434. https://doi.org/10.1111/j.1545-5300.2002.41309.x

[37] Davis, D., Shaver, P.R. and Vernon, M.L. (2004) Attachment Style and Subjective Motivations for Sex. Personality and Social Psychology Bulletin, 30, 1076-1090. https://doi.org/10.1177/0146167204264794

[38] Schachner, D.A. and Shaver, P.R. (2004) Attachment Dimensions and Sexual Motives. Personal Relationships, 11, 179-195.

[39] Dewitte, M. (2012) Different Perspectives on the Sex-Attachment Link: Towards an Emotion-Motivational Account. Journal of Sex Research, 49, 105-124. https://doi.org/10.1080/00224499.2011.576351

[40] DeWall, C.N., et al. (2011) So Far Away from One's Partner, Yet So Close to Romantic Alternatives: Avoidant Attachment, Interest in Alternatives, and Infidelity. Journal of Personality and Social Psychology, 101, 1302-1316. https://doi.org/10.1037/a0025497

[41] Fish, J.N., Pavkov, T.W., Wetchler, J.L. and Bercik, J. (2012) Characteristics of Those Who Participate in Infidelity: The Role of Adult Attachment and Differentiation in Extradyadic Experiences. American Journal of Family Therapy, 40, 214-229. https://doi.org/10.1080/01926187.2011.601192

[42] Russell, V., Baker, L.R. and McNulty, J.K. (2013) Attachment Insecurity and Infidelity in Marriage: Do Studies of Dating Relationships Really Inform Us about Marriage? Journal of Family Psychology, 27, 242-251. https://doi.org/10.1037/a0032118

[43] Allen, E.S. and Baucom, D.H. (2004) Adult Attachment and Patterns of Extradyadic Involvement. Family Process, 43, 467-488. https://doi.org/10.1111/j.1545-5300.2004.00035.x

[44] Brennan, K.A. and Shaver, P.R. (1995) Dimensions of Adult Attachment, Affect Regulation, and Romantic Relationship Functioning. Personality and Social Psychology Bulletin, 21, 267-283. https://doi.org/10.1177/0146167295213008

[45] Sharpsteen, D.J. and Kirkpatrick, L.A. (1997) Romantic Jealousy and Adult Romantic Attachment. Journal of Personality and Social Psychology, 72, 627-640.

[46] Stack, S., Wasserman, I. and Kern, R. (2004) Adult Social Bonds and Use of Internet Pornography. Social Science Quarterly, 85, 75-88.

[47] Wysocki, D.K. and Childers, C.D. (2011) “Let My Fingers Do the Talking”: Sexting and Infidelity in Cyberspace. Sexuality \& Culture: An Interdisciplinary Quarterly, 15, 217-239. https://doi.org/10.1007/s12119-011-9091-4

[48] Muusses, L.D., Kerkhof, P. and Finkenauer, C. (2015) Internet Pornography and Relationship Quality: A Longitudinal Study of within and between Partner Effects of Adjustment, Sexual Satisfaction and Sexually Explicit Internet Material among Newly-Weds. Computers in Human Behavior, 45, 77-84. https://doi.org/10.1016/j.chb.2014.11.077

[49] Hertlein, K.M. and Piercy, F.P. (2012) Essential Elements of Internet Infidelity Treatment. Journal of Marital and Family Therapy, 38, 257-270.

[50] Landripet, I. and Štulhofer, A. (2015) Is Pornography Use Associated with Sexual Difficulties and Dysfunctions among Younger Heterosexual Men? Journal of Sexual Medicine, 12, 1136-1139. https://doi.org/10.1111/jsm.12853

[51] Aviram, I. and Amichai-Hamburger, Y. (2005) Online Infidelity: Aspects of Dyadic Satisfaction, Self-Disclosure, and Narcissism. Journal of Computer-Mediated Communication, 10. https://doi.org/10.1111/j.1083-6101.2005.tb00249.x

[52] Hertlein, K.M. (2011) Therapeutic Dilemmas in Treating Internet Infidelity. American Journal of Family Therapy, 39, 162-173. 
https://doi.org/10.1080/01926187.2010.530927

[53] Hertlein, K.M. (2012) Digital Dwelling: Technology in Couple and Family Relationships. Family Relations, 61, 374-387. https://doi.org/10.1111/j.1741-3729.2012.00702.x

[54] Young, K.S., Griffin-Shelley, E., Cooper, A., O’Mara, J. and Buchanan, J. (2000) Online Infidelity: A New Dimension in Couple Relationships with Implications for Evaluation and Treatment. Sexual Addiction \& Compulsivity, 7, 59-74. https://doi.org/10.1080/10720160008400207

[55] Whitty, M.T. (2005) The Realness of Cybercheating: Men's and Women's Representations of Unfaithful Internet Relationships. Social Science Computer Review, 23, 57-67. https://doi.org/10.1177/0894439304271536

[56] Brand, R.J., Markey, C.M., Mills, A. and Hodges, S.D. (2007) Sex Differences in Self-Reported Infidelity and Its Correlates. Sex Roles, 57, 101-109. https://doi.org/10.1007/s11199-007-9221-5

[57] Gottman, J.M. (1999) The Marriage Clinic: A Scientifically Based Marital Therapy. W. W. Norton \& Company, New York.

[58] Laumann, E.O., Gagnon, J.H., Michael, R.T. and Michaels, S. (1994) The Social Organization of Sexuality: Sexual Practices in the United States. University of Chicago Press, Chicago.

[59] Ickes, W., Dugosh, J.W., Simpson, J.A. and Wilson, C.L. (2003) Suspicious Minds: The Motive to Acquire Relationship-Threatening Information. Personal Relationships, 10, 131-148. https://doi.org/10.1111/1475-6811.00042

[60] Ickes, W., Snyder, M. and Garcia, S. (1997) Personality Influences on the Choice of Situations. In: Hogan, R., Johnson, J.A., Briggs, S.R., Hogan, R., Johnson, J.A. and Briggs, S.R., Eds., Handbook of Personality Psychology, Academic Press, San Diego, 165-195. https://doi.org/10.1016/B978-012134645-4/50008-1

[61] Costa, P.T. and McCrae, R.R. (1992) Normal Personality Assessment in Clinical Practice: The NEO Personality Inventory. Psychological Assessment, 4, 5-13.

[62] Brennan, K.A., Clark, C.L. and Shaver, P.R. (1998) Self-Report Measurement of Adult-Attachment: An Integrative Overview. In: Simpson, J.A. and Rholes, W.S., Eds., Attachment Theory and Close Relationships, Guilford Press, New York, 46-76.

[63] Lafontaine, M-F. and Lussier, Y. (2003) Bidimensional Structure of Attachment in Love: Anxiety over Abandonment and Avoidance of Intimacy. Canadian Journal of Behavioural Science, 35, 56-60. https://doi.org/10.1037/h0087187

[64] Lafontaine, M-F., Brassard, A., Lussier, Y., Valois, P., Shaver, P.R. and Johnson, S.M. (2016) Selecting the Best Items for a Short-Form of the Experiences in Close Relationships Questionnaire. European Journal of Psychological Assessment. 32, 140-154.

[65] Spanier, G.B. (1976) Measuring Dyadic Adjustment: New Scales for Assessing the Quality of Marriage and Similar Dyads. Journal of Marriage and the Family, 38, 1528. https://doi.org/10.2307/350547

[66] Sabourin, S., Valois, P. and Lussier, Y. (2005) Development and Validation of a Brief Version of the Dyadic Adjustment Scale with a Nonparametric Item Analysis Model. Psychological Assessment, 17, 15-27. https://doi.org/10.1037/1040-3590.17.1.15

[67] Nowinski, J.K. and Lopiccolo, J. (1979) Assessing Sexual Behaviors in Couples. Journal of Sex \& Marital Therapy, 5, 225-243. https://doi.org/10.1080/00926237908403731

[68] Preacher, K.J., Rucker, D.D. and Hayes, A.F. (2007) Addressing Moderated Media- 
tion Hypotheses: Theory, Methods, and Prescriptions. Multivariate Behavioral Research, 42, 185-227. https://doi.org/10.1080/00273170701341316

[69] Muthén, L.K. and Muthén, B.O. (2008) Mplus Usersguide. 5th Edition, Muthén \& Muthén, Los Angeles.

[70] Wothke, W. (2000) Longitudinal and Multigroup Modeling with Missing Data. In: Little, T.D., Schnabel, K.U. and Baumert, J., Eds., Modeling Longitudinal and Multilevel Data: Practical Issues, Applied Approaches, and Specific Examples, Lawrence Erlbaum Associates Publishers, Mahwah, 219-240.

[71] Hoyle, R.H. (1995) The Structural Equation Modeling Approach: Basic Concepts and Fundamental Issues. In: Hoyle, R.H., Ed., Structural Equation Modeling: Concepts, Issues, and Applications, Sage Publications, Thousand Oaks, 1-15.

[72] Browne, M.W. and Cudeck, R. (1993) Alternative Ways of Assessing Model Fit. In: Bollen, K.A. and Long, J.S., Eds., Testing Structural Equation Models, Sage, Newbury Park, 136-192.

[73] Amato, P.R. (2010) Research on Divorce: Continuing Developments and New Trends. Journal of Marriage and the Family, 72, 650-666.

https://doi.org/10.1111/j.1741-3737.2010.00723.x

[74] Bouchard, G. and Arseneault, J. (2005) Length of Union as a Moderator of the Relationship between Personality and Dyadic Adjustment. Personality and Individual Differences, 39, 1407-1417. https://doi.org/10.1016/j.paid.2005.05.005

[75] Daspe, M., Sabourin, S., Péloquin, K., Lussier, Y. and Wright, J. (2013) Curvilinear Associations between Neuroticism and Dyadic Adjustment in Treatment-Seeking Couples. Journal of Family Psychology, 27, 232-241. https://doi.org/10.1037/a0032107

[76] Widiger, T.A. and Mullins-Sweatt, S.N. (2009) Five-Factor Model of Personality Disorder: A Proposal for DSM-V. Annual Review of Clinical Psychology, 5, 197220. https://doi.org/10.1146/annurev.clinpsy.032408.153542

[77] Ghosh, A. and Dasgupta, S. (2015) Psychological Predictors of Facebook Use. Journal of the Indian Academy of Applied Psychology, 41, 101-109.

[78] Muscanell, N.L. and Guadagno, R.E. (2012) Make New Friends or Keep the Old: Gender and Personality Differences in Social Networking Use. Computers in Human Behavior, 28, 107-112. https://doi.org/10.1016/j.chb.2011.08.016

[79] Wilson, K., Fornasier, S. and White, K.M. (2010) Psychological Predictors of Young Adults' Use of Social Networking Sites. Cyberpsychology, Behavior, and Social Networking, 13, 173-177. https://doi.org/10.1089/cyber.2009.0094

[80] Delevi, R. and Weisskirch, R.S. (2013) Personality Factors as Predictors of Sexting. Computers in Human Behavior, 29, 2589-2594. https://doi.org/10.1016/j.chb.2013.06.003

[81] Barnes, G.E., Malamuth, N.M. and Check, J.V. (1984) Personality and Sexuality. Personality and Individual Differences, 5, 159-172.

[82] Kenny, D.A., Kashy, D.A. and Cook, W.L. (2006) Dyadic Data Analysis. Guilford Press, New York.

[83] Schneider, J.P. (2002) The New "Elephant in the Living Room": Effects of Compulsive Cybersex Behaviors on the Spouse. In: Cooper, A., Ed., Sex and the Internet: $A$ Guidebook for Clinicians, Brunner-Routledge, New York, 169-186.

[84] Lambert, N.M., Negash, S., Stillman, T.F., Olmstead, S.B. and Fincham, F.D. (2012) A Love That Doesn't Last: Pornography Consumption and Weakened Commitment to One's Romantic Partner. Journal of Social and Clinical Psychology, 31, 410-438. 
Submit or recommend next manuscript to SCIRP and we will provide best service for you:

Accepting pre-submission inquiries through Email, Facebook, LinkedIn, Twitter, etc. A wide selection of journals (inclusive of 9 subjects, more than 200 journals)

Providing 24-hour high-quality service

User-friendly online submission system

Fair and swift peer-review system

Efficient typesetting and proofreading procedure

Display of the result of downloads and visits, as well as the number of cited articles Maximum dissemination of your research work

Submit your manuscript at: http://papersubmission.scirp.org/

Or contact $\underline{\text { sn@scirp.org }}$ 